\title{
Effect Of Internet Addiction On Academic Performance And Mental Health Of Medical Students
}

\author{
Ijaz Ali, Ommia Kalsoom, Syed Asif Jahanzeb Kazmi, Tahir Ahmad Munir, Zanib Qayyum, Naheed Akhter, \\ Athar Ahmad Jan \\ - - - - - - - - - - - - - - - - - - - - - - - - - - - - - -
}

ABSTRACT:

Objective: Objective of this study was to determine internet addiction and its impact on mental health and academic performance in medical students.

Methodology: One hundred medical students (male: 50, female: 50) aged 18-21 years were selected by convenience sampling in this cross-sectional study in Mahi-ud-din Islamic Medical college Mirpur AJK. A questionnaire of Young's internet addiction test was used to identify the prevalence of Internet addiction, the purposes of Internet use, and their priority levels. Frequencies and level of mental health was measured using Mental health Battery by Singh and Gupta. Chi square test was applied and $\mathrm{p}$ value $<0.05$ was considered significant.

Results: Out of 100 students, 46 (male: 28 , female: 18) were found to be slightly addicted, 53 students were average online users and only 01 male was severely addicted. There was no significant difference between male and female students in addiction level. However, males were more addicted than females. The major use of Internet was to communicate with friends and family and to watch songs and movies. 51 students used the Internet to assess information for their educational and learning activities. Some students with overuse of the Internet lead to insufficient sleep and affected their concentration levels in the class.

Conclusion: Medical students experiencing problems due to Internet overuse and experiencing poor academic progress and lack of concentration while studying. The main use of the Internet was to communicate with friends and family and for entertainment.

Key Words: addiction, Internet, medical students, entertainment.

INTRODUCTION:

Internet, a piece of technology and revolutionary invention, can be accessed from smart phones, tablets, laptops, and desktop computers anywhere and on all sorts of different

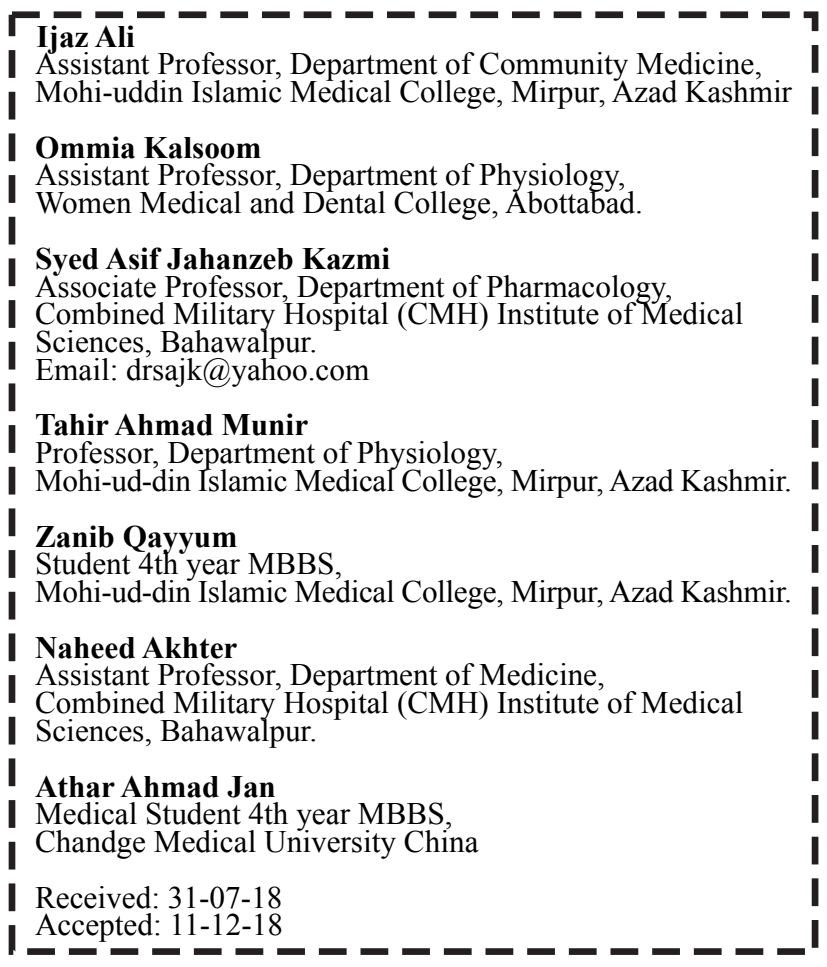

mediums. According to International Telecommunication Union about 3.2 billion people ( $50 \%$ of the world population) was on line in 2015 , which raised to $>51 \%$ by 2017 ; out of which $81 \%$ of the internet was used by developed countries and rest by the developing countries ${ }^{1}$. No doubt, if used properly, it is a very good source for information, communication, entertainment, commercials, education assistance, economics, culture and for scientific knowledge ${ }^{2}$. Over the last few years the use of this electronic informative source is on increase by medical student due to its costeffectiveness and the delivery of information from any source in no time ${ }^{3,4}$. Sstudents and teenagers are considered to be the main population becoming Internet addict compared to other population groups ${ }^{5}$. The students of internet addiction show academic problems, depression, anxiety, change in lifestyle, aggression, sleeping and physical disorders, phobias and a change in attitude to their emotions $s^{6,7}$. Its continues use even results in serious consequences on lifestyle change, ignoring health and main social activities ${ }^{8,9}$.

Mental health is "a state of well-being in which the individual realizes his or her own abilities, can cope with the normal stresses of life, can work productively and fruitfully and is also able to make contribution to his/her community"10,11. The signs of poor mental health include poor concentration, easy distraction, difficulty to make decisions, loss of interest in day-to-day activities, low mood, tiredness and lack of energy, irritability and short temper and difficult to control emotions ${ }^{12}$. 
Objective of this study was to see the frequency of internet use among medical students and its effect on academic performance and mental health.

\section{METHODOLOGY:}

This cross-sectional study was conducted on 100 undergraduate medical students (male: 50 , female: 50 ) from first year MBBS class of Mohi-ud-Din Islamic Medical College Mirpur AJK. The students were selected by convenience sampling and any student with previous psychological illness and other systemic illness were excluded from the study. The study was approved by the ethical committee of the institution and all the participants signed the informed written consent Performa.

A standard Young's Internet Addiction Test ${ }^{13} 20$ items with responses on a 5 point Likert scale was distributed among the students to measures mild, moderate and severe levels of Internet addiction. The student response for each questionnaire ranged from 0 to $5: 5=$ always, $4=$ often, 3 $=$ frequently, $2=$ occasionally, $1=$ rarely, and $0=$ does not apply. The IAT score was calculated by adding the scores obtained for all 20 items, (score 20-49 points: Average online user and surf the web for long at times, but have control over usage, 50-79 points: representing frequent Internet use and need consideration due to full impact on life, 80-100 points: associated with significant Internet usage and need to address the problems (students showing poor academic performance) caused by Internet usage.

A $2^{\text {nd }}$ self-designed questionnaire was distributed among the students to identify the purposes of Internet use, and their priority level for different purposes. The Internet priority level was marked from "no, least, rarely, average, always". The items included to give various reasons for Internet use: Communicating with friends and families, Education and learning activities, Downloading film and music, Reading news, Learning computer applications, Watching moves and songs online, Playing online games Internet shopping, Writing weblogs, Uploading /downloading exploiting videos and images, Scientific search, Email checking, making friends and Solicitation (the act of asking for or trying to obtain something from someone). The general questions regarding mode of Internet (mobile, laptop, or desktop), any other purpose of Internet use was also asked. Additionally, monthly cost of Internet use and the impact of Internet use on their academic progress and daily activities was also assessed.

Frequencies and level of mental health of the students was measured using Mental health Battery by Singh and Gupta ${ }^{14}$. The Domains of Mental Health consist of Emotional Stability, Self-Concept, Autonomy, Security-Insecurity, Adjustment and Mental Capacity. Each domain consisted of at least 10 questionnaire.

After explaining the purpose of this study, questionnaires were distributed to all students during a lecture slot and were collected after the students filled them. The students were asked not to write their names in the questionnaire and chose more than one option of the questions.

The data were processed and analyzed using SPSS version 16. For descriptive statistics the frequency distribution was used.

\section{RESULTS:}

A total of 100 students were inducted in the study. The average age was $19.71 \pm 0.90$. Table 1 shows internet addiction levels among the medical students. Out of 100 students, 46 students were found to be facing average problems and were found to be slightly addicted to internet use. The total percentage among male were more as compared to female students. When Internet use and its addiction level was compared between male and female students was seen between male and female medical students. In our study about $32(32 \%)$ females as compared to $21(21 \%)$ male students were moderate user of internet and faced frequent problems, while high addiction level with significant problem due to internet was only seen in one male student. Twenty six (26\%) of the student showed that they always (scale 5) fear that life without the Internet would be boring, empty, and joyless, while $38 \%$ were often (scale 4 ) found addict for saying "just a few more minutes" when online. All the student agreed that internet do affect their life. On the other hand $26 \%$ agreed that their performance suffer due to internet frequently (scale 3 ), $28 \%$ occasionally (scale 2 ) use internet while going out with others and $66 \%$ rarely (scale 1) make frequent relation with online users. About $46 \%$ of the students were facing mild problems due to internet, $53 \%$ facing frequent problem and only one $(01 \%)$ student was facing severe problem due to internet use and showed depression, angry, sleep deprivation, decreased ability to concentrate at work and education especially by those facing severe and frequent internet problems.

Table 2 shows purpose of internet regarding its priority. The purpose of Internet use vary among the students. The majority of students showed priority for use of some internet aspects such as communicating with friends and family members (71\%), watching movies and songs on line (62\%), education and learning activities (54\%), and downloading films and music (53\%). Other major priorities include uploading /downloading exploiting videos and images (32\%), learning computer applications $(30 \%)$, making new friends $(30 \%)$ and scientific search (30\%). None of the students declared internet to be of any significance, however, solicitation (68\%), writing blogs (64\%) and internet shopping (43\%), playing online games $(42 \%)$ were among their least prioritized. Similarly, checking emails, making new friends, uploading/downloading exploiting images and videos that harm/abuse others, reading news and scientific search were also the last priority among some students. About $15 \%$ of the students mentioned that they had lack of concentration 
Ijaz Ali, Ommia Kalsoom, Syed Asif Jahanzeb Kazmi, Tahir Ahmad Munir, Zanib Qayyum, Naheed Akhter, Athar Ahmad Jan

in their classes with poor academic progress due to overuse of the Internet. Most of the students $(62 \%)$ were using internet at evening and night time. About 51 (51\%) students spent about 500 Rs per month on internet, about 39 (39\%) spent less than 500 Rs.

Table 3 shows distribution of mental health items according to the mental health battery by Singh and Gupta. The result showed that out of 100 students only 06 students $(06 \%)$ scored more than 90 with excellent mental health, while 49 students $(49 \%)$ scored between 70 to 90 and fall in good mental health category, whereas 31 students (31\%) scored between 50 to 60 fall in average mental health. Only 10 student $(10 \%)$ were in poor scoring between 30 to 49 and 04 students $(04 \%)$ fall in very poor mental health category scoring less than 29. The female and male showed an equal percentage $(03 \%)$ for excellent mental health while female have better percentage for good mental health while male were slightly higher in very poor mental health compared to females.

\section{DISCUSSION:}

Our study was conducted on 100 medical students to assess Internet use, Internet addiction levels. Our results showed that 46 students were slightly (50-79 score) addicted with a male students predominance. Our results are in agreement

\begin{tabular}{|l|c|c|c|c|}
\hline \multicolumn{1}{|c|}{ Level of Addiction } & Range score & Male & Female & Total \\
\hline Mild user Facing average problems & $20-49$ & 28 & 18 & 46 \\
\hline Moderate internet user Facing frequents problems & $50-79$ & 21 & 32 & 53 \\
\hline Internet addict Facing significant problems & $80-100$ & 01 & 0 & 01 \\
\hline
\end{tabular}

Table 1. Internet addiction test among medical students

\begin{tabular}{|l|c|c|c|}
\hline \multicolumn{1}{|c|}{ Items } & Major priority & Average priority & No priority \\
\hline Communicating with friends and families & 71 & 20 & 09 \\
\hline Education and learning activities & 54 & 29 & 17 \\
\hline Reading news & 25 & 43 & 32 \\
\hline Learning computer applications & 30 & 34 & 36 \\
\hline Watching moves and songs online & 62 & 25 & 13 \\
\hline Playing online games & 29 & 29 & 42 \\
\hline Internet shopping & 18 & 39 & 43 \\
\hline Writing weblogs & 12 & 24 & 64 \\
\hline Uploading /downloading exploiting videos and images & 32 & 30 & 38 \\
\hline Scientific search & 30 & 44 & 26 \\
\hline Email checking & 26 & 38 & 36 \\
\hline Chatting with new people & 30 & 35 & 35 \\
\hline Solicitation & 13 & 19 & 68 \\
\hline
\end{tabular}

Table 2. Purpose of internet use regarding its priority

\begin{tabular}{|l|c|c|c|c|c|}
\hline & $\begin{array}{c}\text { Excellent 90 } \\
\text { and above }\end{array}$ & $\begin{array}{c}\text { Good Between } \\
70-90\end{array}$ & $\begin{array}{c}\text { Average Between } \\
50-69\end{array}$ & $\begin{array}{c}\text { Poor Between } \\
30-49\end{array}$ & $\begin{array}{c}\text { Very Poor } \\
\text { Below 29 }\end{array}$ \\
\hline Male & $03(3 \%)$ & $20(20 \%)$ & $19(19 \%)$ & $05(05 \%)$ & 03 \\
\hline Female & $03(3 \%)$ & $29(29 \%)$ & $12(12 \%)$ & $05(05 \%)$ & 01 \\
\hline
\end{tabular}

Table 3. Frequency distribution of items of Mental Health Scale 
with a number of studies who showed that men are more susceptible than girls ${ }^{15-17}$. The higher incidence of IA in our study is related to more social freedom in males, more friends in cyberspace and more membership in chat social network. These results are not consistent with Rogers et $\mathrm{al}^{18}$ who reported excessive use of the Internet among female to update information, access knowledge, and contact with friends and family, spend leisure time, and online shopping, while a study done by Vyjayanthi et $\mathrm{al}^{19}$ reported equal amount of Internet usage among both sex groups.

In our study 46 students were mild internet user facing average problems due to internet use, 53 student were using internet frequently and one student was found to be internet addict facing academic performance. Our results are in consistent with a number of studies ${ }^{20,21}$ who showed that the Internet addiction has negative affect on academic performance and is associated with poor mental health due to Internet overuse for purposes other than studies, however, there are studies who reported that Internet addiction does not affect students' academic performance or Internet addiction $^{22}$.

Mental health, is a state of well-being in which the person realizes own potential, the abilities which he or she can cope with the normal stresses of life, can work productively and fruitfully, and can make a contribution to the community. The IA leeds the person towards power mental health and decreases the student academic performance ${ }^{21,23}$.

Our results showed majority of the student prioritized Internet use for communicating with their friends and family members, watching movies and songs on line and for learning activities to update their knowledge. These results are consistent with a similar study ${ }^{24}$ conducted among adults from Taiwan and students of Guilan ${ }^{25}$. While in the study done by Ansari et $\mathrm{al}^{26}$, there were no statistically significant relationships. The stress arisen in the students as a result of far from their home and family members, fill their loneliness and compensation for mental support feelings of loneliness they may indulge in and spending more time on the internet ${ }^{27}$ showing that a lack of psychological support cause students to overuse the internet. Our results showed least internet usage for solicitation, writing weblogs, internet shopping and playing online games.

\section{CONCLUSION:}

In our study we found major use of internet was for communication with their family and friends, entertainment and for academic purposes. The problem experienced by the medical students due to their Internet use came out to be lack of proper sleep, poor mental concentration towards their studies and poor academic performance.

\section{REFERENCES:}

1. "World Internet Users Statistics and 2016 World Population Stats" Key ICT indicators for developed and developing countries and the world (totals and penetration rates),
International Telecommunication Union (ITU).

2. Bahri N, Sadegh ML, Khodadost L, Mohammadzade J, Banafsheh E. Internet addiction status and its relation with students' general health at Gonabad Medical University. Modern Care Journal 2011;8:166-73.

3. Azizollah A, Enam A, Charkhat G, Sanam B, Gholamreza G. The Association of Internet Addiction with Academic, Achievement, Emotional Intelligence and Strategies to Prevention of them from Student's Perspectives. IJHCS 2016:3;1646-56.

4. Mahdizadeh J, Valinejadi A, Pooyesh B, Jafari F, Kahouei M. Students' attitudes towards impact of the health department website on their health literacy in Semnan University of Medical Sciences. Electron Physician. 2018;10:6164-71.

5. Upadhayay N, Guragain S. Internet use and its addiction level in medical students. Adv Med Educ Pract. 2017;8:641-7.

6. Zhang MWB, Lim RBC, Lee C, Ho RCM. Prevalence of Internet Addiction in Medical Students: a Meta-analysis. Acad Psychiatry. 2018; 42:88-93.

7. Langarizadeh M, Naghipour M, Tabatabaei SM, Mirzaei A, Vaghar ME. Prediction of internet addiction based on information literacy among students of Iran University of Medical Sciences. Electron Physician. 2018;10:6333-40.

8. Alzayyat A, Al-Gamal E, Ahmad MM. Psychosocial correlates of Internet addiction among Jordanian university students. J Psychosoc Nurs Ment Health Serv. 2015;53:43-51.

9. Athanasopoulou C, Välimäki M, Koutra K, Löttyniemi E, Bertsias A, Basta M, et al. Internet use, e Health literacy and attitudes toward computer/internet among people with schizophrenia spectrum disorders: a cross-sectional study in two distant European regions. BMC Med Inform Decis Mak. $2017 ; 17: 136-42$.

10. Katie Bessière, MS,1 Sarah Pressman, Sara Kiesler and Robert Kraut. Effects of Internet Use on Health and Depression: A Longitudinal StudyJ Med Internet Res. 2010;12(1):e6. doi: 10.2196/jmir.1149.

11. World Mental Health Day, 10 October, "young people and mental health in a changing world".2018.

12. Sebastian Hökby, Gergö Hadlaczky, Joakim Westerlund, Danuta Wasserman, Judit Balazs, Arunas Germanavicius et al. Are Mental Health Effects of Internet Use Attributable to the Web-Based Content or Perceived Consequences of Usage? A Longitudinal Study of European Adolescents JMIR Ment Health. 2016; 3(3):e31. doi: 10.2196/mental.5925.

13. Kimberly S. Young. Measures the presence and severity of Internet and technology addiction, which is now viewed as a clinical disorder, requiring assessment and treatment.

14. Singh \& Gupta (2008). Manual for mental health battery. National Wiley. psychological Corporation, Agra.

15. Lichan Liang, Dan Zhou, Chunyong Yuan, Aihui Shao, Yufang Bian. Gender differences in the relationship between internet addiction and depression: A cross-lagged study in Chinese adolescents. Computers in Human Behavior. 2016;63:46370.

16. Magali Dufour, Natacha Brunelle, Joel Tremblay. Gender Difference in Internet Use and Internet Problems among Quebec High School Students. Can J Psychiatry. 2016;61:6638 .

17. Guan SSA, Subrahmanyam K. Youth Internet use: risks and opportunities. Curr Opin Psychiatry.2009;22:351-356. 
18. Roger LR, Bruce RK, Jo AA. Young Female Users of Social Media and Internet Addiction. J Mass Communicat Journalism 2014; 4:2-8.

19. Vyjayanthi S, Surabhi M, Mohammad Afraz, Sundarnag G. Medica Innovatica Gender differences in the prevalence and features of internet addiction among Indian college students. 2014;3: 49-53.

20. Babadi-AZ, Zamani BE, Abedini Y, Akbari H, Hedayati N. The Relationship between Mental Health and Addiction to Mobile Phones among University Students of Shahrekord, Iran. Addict Health. 2014;6:93-99.

21. Loredo ES, de Souza BD, da Silva EO, Lucchetti ALG, Lucchetti G. The Use of Smartphones in Different Phases of Medical School and its Relationship to Internet Addiction and Learning Approaches. J Med Syst. 2018;42:106-12.

22. Younes F, Halawi G, Jabbour H, El Osta N, Karam L, Hajj $\mathrm{A}$, et al. Internet Addiction and Relationships with Insomnia, Anxiety, Depression, Stress and Self-Esteem in University Students: A Cross-Sectional Designed Study. PLoS One. 2016;11:9-15.
23. Djoko R, Sumardj O, Djuara P, Sri H. Internet access and usage in improving student' self-directed learning in Indonesia open University. TOJDE 2016;17: 30-41.

24. Cao F, Su L. Internet addiction among Chinese adolescents: prevalence and psychological features. Child Care Health Dev. 2007;33(3): 275-81

25. Ko CH, Yen JY, Chen CS, Yeh YC, Yen CF. Predictive values of psychiatric symptoms for internet addiction in adolescents: a 2-year prospective study. Arch Pediatr Adolesc Med. 2009; 163(10): 937-43.

26. Ansari H, Ansari-Moghaddam A, Mohammadi MM, Peyvand $\mathrm{M}$, Amani Z, Arbabisarjou A. Internet addiction and happiness among medical sciences students in southeastern iran. Healt Scop. 2016; 5(2).e33600.

27. Carol S Bond. Learning to use the Internet as a study tool: A review of available resources and exploration of students' priorities. Health Information \& Libraries Journal 2018; 23:189-96 